\title{
Antibacterial Efficacy of Gold and Silver Nanoparticles Functionalized with the Ubiquicidin (29-41) Antimicrobial Peptide
}

\author{
Enrique Morales-Avila, ${ }^{1}$ Guillermina Ferro-Flores, ${ }^{2}$ \\ Blanca E. Ocampo-García, ${ }^{2}$ Gustavo López-Téllez, ${ }^{3}$ Johnny López-Ortega, ${ }^{1}$ \\ Diana G. Rogel-Ayala, ${ }^{1}$ and Diego Sánchez-Padilla ${ }^{1}$ \\ ${ }^{1}$ Universidad Autónoma del Estado de México, Facultad de Química, Toluca, MEX, Mexico \\ ${ }^{2}$ Instituto Nacional de Investigaciones Nucleares, 52750 Ocoyoacac, MEX, Mexico \\ ${ }^{3}$ Universidad Autónoma del Estado de México, Centro Conjunto de Investigación en Química Sustentable UNAM/UAEM, \\ 50200 Toluca, MEX, Mexico \\ Correspondence should be addressed to Enrique Morales-Avila; emoralesav@uaemex.mx
}

Received 21 December 2016; Accepted 6 March 2017; Published 26 March 2017

Academic Editor: Piersandro Pallavicini

Copyright (c) 2017 Enrique Morales-Avila et al. This is an open access article distributed under the Creative Commons Attribution License, which permits unrestricted use, distribution, and reproduction in any medium, provided the original work is properly cited.

\begin{abstract}
Recent studies have demonstrated that drug antimicrobial activity is enhanced when metallic nanoparticles are used as an inorganic support, obtaining synergic effects against microorganisms. The cationic antimicrobial peptide ubiquicidin 29-41 (UBI) has demonstrated high affinity and sensitivity towards fungal and bacterial infections. The aim of this research was to prepare and evaluate the antimicrobial efficacy of engineered multivalent nanoparticle systems based on silver or gold nanoparticles functionalized with UBI. Spectroscopy techniques demonstrated that NPs were functionalized with UBI mainly through interactions with the $-\mathrm{NH}_{2}$ groups. A significant increase in the antibacterial activity against Escherichia coli and Pseudomonas aeruginosa was obtained with the conjugate AgNP-UBI with regard to that of AgNP. No inhibition of bacterial growth was observed with AuNP and AuNP-UBI using a nanoparticle concentration of up to $182 \mu \mathrm{g} \mathrm{mL}^{-1}$. Nonetheless, silver nanoparticles conjugated to the UBI antimicrobial peptide may provide an alternative therapy for topical infections.
\end{abstract}

\section{Introduction}

A wide variety of nanotechnological devices for the treatment of infectious diseases have been developed, including microemulsions [1], vaccines [2,3], and metallic- $[4,5]$, inorganic[6], lipid-, and polymeric-based nanoparticles (NPs) [7].

Metallic NPs such as silver (AgNP) and gold (AuNP) show unique and considerably distinct physical, chemical, and biological properties due to their high surface-to-volume ratio, with which surfaces can be modified with ligands containing functional groups, providing an electrostatic or steric stabilization [8].

The antibacterial activity of AgNPs against a broad spectrum of bacteria is well-known. AgNPs have been conjugated to different molecules with antibacterial activity in order to obtain synergic effects, such as poly(ethyleneimine) [9], amoxicillin [10], polysaccharides [11], peptides [12], surfactants, and polymers [13].

Recent studies demonstrated that AuNPs also have antimicrobial activity [14]. Different techniques for NP surface synthesis and functionalization with antimicrobial drugs through covalent or noncovalent interactions have been described, such as amoxicillin-coated AuNPs [15], vancomycin-capped AuNPs [16], and ampicillin-, streptomycin-, and kanamycin-conjugated AuNPs [17], as well as cefaclor[18] and aminoglycoside-conjugated AuNPs [19]. The aforementioned studies are in agreement that the use of nanoparticles combined with other antimicrobial effects can help reduce intrinsic toxicity of nanoparticles for mammalian cells, enhance the microbicidal effect by increasing damage 
mechanisms, and diminish the probability development of resistance.

Antimicrobial peptides (AMP) represent ancient host defence effector molecules. The basis of antimicrobial activity is the interaction of the peptide's cationic domains (positively charged) with the surface of microorganisms (negatively charged). The membranes of the latter expose negatively charged lipoteichoic acid and phospholipids while, in normal mammalian cells, negatively charged lipids face the cytoplasm. These properties explain the poor binding of cationic peptides to mammalian cells and the selective binding to bacteria in physiological conditions [20].

The cationic antimicrobial peptide ubiquicidin is present in human skin. Several studies have shown that the synthetic antimicrobial peptide fragment ubiquicidin (29-41) (TGRAKRRMQYNRR; $1,693 \mathrm{Da}$ ) is a very sensitive and specific agent for the scintigraphic detection of bacterial and fungal infections in humans, making the differentiation between an infection and noninfectious processes possible. [21-25]. The broad spectrum of antimicrobial peptides makes them suitable for future medical applications; in this sense, nanotechnology provides promising alternatives for peptide transport and targeted delivery with strongly enhanced biocidal properties and significant reduction of toxicity.

The aim of this research was to evaluate the antimicrobial efficacy of engineered multivalent nanoparticle systems based on silver or gold nanoparticles functionalized with the antimicrobial peptide ubiquicidin 29-41 (UBI).

\section{Material and Methods}

2.1. Materials. Ubiquicidin 29-41 [H-Thr-Gly-Arg-Ala-LysArg-Arg-Met-Gln-Tyr-Asn-Arg-Arg-OH; MW 1693.0] (Bachem, USA), Muller-Hilton agar (Bioxon, Becton Dickinson), silver nitrate $\left(\mathrm{AgNO}_{3}\right)$, tetrachloroauric acid $\left(\mathrm{HAuCl}_{4} \cdot 3 \mathrm{H}_{2} \mathrm{O}\right)$, trisodium citrate dihydrate $\left(\mathrm{Na}_{3} \mathrm{C}_{6} \mathrm{H}_{5} \mathrm{O}_{7}\right)$, sodium dodecyl sulfate, and solvents were purchased from Sigma-Aldrich Chemical Co. and used as received. All water was deionized and sterile, obtained from a MilliQ ${ }^{\circledR}$ purified water system.

\subsection{Synthesis and Stabilization of Silver and Gold Nanoparti-} cles. Gold nanoparticles were prepared by citrate reduction of tetrachloroauric acid according to the method described by Kimling et al. [26]. Silver nanoparticles were prepared according to Dong et al.s procedure [27]. Nanoparticles were purified by dialysis against injectable-grade water during $24 \mathrm{~h}$ and sterilized by membrane filtration with a $0.22 \mu \mathrm{m}$ filter (Millipore, Bedford, Massachusetts, USA). Posteriorly, NPs were stabilized with the sodium dodecyl sulfate (SDS) surfactant in order to prevent NP aggregation and establish a suitable surface for peptide adsorption. SDS $\left(1 \mathrm{~mL}, 0.05 \%_{\mathrm{w} / \mathrm{w}}\right)$ was added to $100 \mathrm{~mL}$ of the nanoparticle suspension (AgNP or AuNP) and stirred for $10 \mathrm{~min}$. The mixture was then purified by size-exclusion chromatography (PD-10 column) using injectable-grade water as eluent. The peak obtained (3.0-4.0 mL) corresponded to the void volume of the column, which contained AuNP-SDS or AgNP-SDS. The volume mean diameter measured by DLS was not significantly different from nonstabilized nanoparticles.
2.3. Determination of Gold and Silver Content. Gold content was quantified through potentiometric titration of gold (III). A constant volume of gold nanoparticles was oxidized by a $\mathrm{HF} / \mathrm{aqua}$ regia mixture and determined through Robles et al's methodology [28]. Silver content was determined using a back titration, following Volhard's method described by Xu et al. [29].

2.4. Conjugation and Standardization of Stabilized Nanoparticles to the UBI Peptide. In order to determine the stability of the NP-UBI colloidal suspension, different volumes (from $20 \mu \mathrm{L}$ to $100 \mu \mathrm{L}$ ) of $20 \mu \mathrm{M}$ UBI were added to $1 \mathrm{~mL}$ of stabilized SDS-NPs and $t$ were then stirred for 15 minutes at room temperature. Z-potential (Microtrac, USA) was then measured to determine the peptide's effect on colloidal stability.

Once the most stable suspension was selected, it was scaled as follows: $750 \mu \mathrm{L}$ of UBI (29-41) $20 \mu \mathrm{M}(1.5 \times$ $10^{-8} \mathrm{~mol}$ ) was added to $25 \mathrm{~mL}$ of stabilized SDS-NPs. The peptide/NP radio was calculated and adjusted to obtain 5-20 peptides per nanoparticle. Finally, functionalized NPs were purified and concentrated using ultracentrifugation $\left(22,000 \mathrm{rpm}\right.$ for 20 minutes at $\left.-4^{\circ} \mathrm{C}\right)$. The final suspension of AuNP-UBI or AgNP-UBI was spectrophotometrically adjusted to an absorbance of 1 u.a. and stored (in darkness at $4^{\circ} \mathrm{C}$ ) for further use.

\subsection{Physiochemical Characterization}

2.5.1. UV-Vis Spectroscopy. Absorption spectra, in the range of $400-700 \mathrm{~nm}$, were obtained with a Thermo Genesys $10 \mathrm{~S}$ spectrometer using a $1 \mathrm{~cm}$ quartz cuvette. Conjugates were measured by UV-Vis analysis to monitor the AuNP, AuNPUBI, AgNP, and AgNP-UBI surface plasmon resonance band.

2.5.2. Particle Size and Zeta Potential. AgNPs and AuNPs functionalized to UBI were measured $(n=5)$ using a particle size (dynamic light scattering) and Z-potential analyser (Nanotrac Wave, Model MN401, Microtract, FL, USA).

2.5.3. Infrared Spectroscopy. The FT-IR spectra of lyophilized samples were acquired on a Perkin Elmer System 2000 spectrometer with an ATR platform (Pike Technologies) by applying Attenuated Total Reflection Fourier Transform Infrared (ATR-FTIR) spectroscopy from 570 to $4400 \mathrm{~cm}^{-1}$.

2.5.4. Raman Spectroscopy. Raman spectra of the samples were performed on a MicroRaman OLYMPUS BX $41 \mathrm{spec}-$ trometer with a wavelength of $632.817 \mathrm{~nm}$, a D0.6 filter, and a 100 microhole filter/array. Ten scans of $60 \mathrm{~s}$ were acquired on a pretreated glass cover (washed in three steps): $1 \mathrm{HNO}_{3} / 3 \mathrm{HCl}(\mathrm{v} / \mathrm{v})$ solution, bidistilled water, and injectable water. $10 \mu \mathrm{L}$ aliquots of the sample were deposited and dried under nitrogen atmosphere at room temperature in a laminar flow hood.

2.5.5. XPS Spectroscopy. X-ray photoelectron spectra were acquired on a Jeol JPS 9200 spectrometer equipped with a MgKR X-ray source operated at $10 \mathrm{kV} / 20 \mathrm{~mA}$ and calibrated 
using $\mathrm{Au} 4 \mathrm{f}_{7 / 2}(84.0 \mathrm{eV})$ and $\mathrm{Ag} 3 \mathrm{~d}_{5 / 2}(368.2 \mathrm{eV})$ from foil samples. The collection was made using 20 scans for $\mathrm{Au}$ $4 \mathrm{f}$ and $\mathrm{Ag} 3 \mathrm{~d}$ with energy step size of $0.1 \mathrm{eV}$. The binding energies were referenced to the $\mathrm{C} 1 \mathrm{~s}$ peak at $284.3 \mathrm{eV}$. From all spectra, a Shirley background was subtracted to perform the peak fitting with a symmetric Gauss-Lorentz sum function (SpecSurf software).

2.6. Microbiological Evaluation. To determine the antibacterial efficacy of the conjugates, Escherichia coli (ATCC 8739) and Pseudomonas aeruginosa (ATCC 27853) were used as Gram-negative models because of their epidemiologic and clinical importance. Antimicrobial activity of the NPs with or without conjugation was expressed in terms of minimum inhibitory concentration (MIC). Evaluated NPs and conjugates were AuNP, AuNP-SDS, AuNP-UBI, AgNP, AgNP-SDS, AgNP-UBI, and UBI (free peptide). $\mathrm{NaCl} 0.9 \%$ solution was employed as a growth control. Due to the high difficulty in determining the exact nanoparticle concentration, all nanoparticle suspensions and conjugates were standardized spectrophotometrically to 1 a.u. of absorbance and expressed as mass silver or gold concentrations. Titration showed that the standardized solutions contained $637 \pm 74 \mu \mathrm{g} \mathrm{mL}^{-1}$ of $\mathrm{Au}$ and $588 \pm 19 \mu \mathrm{g} \mathrm{mL}^{-1}$ of Ag. To obtain a range in nanoparticle concentrations, 1, 2, 3, 4, and $5 \mathrm{~mL}$ aliquots of standardized NPs were placed in test tubes and completed to $6 \mathrm{~mL}$ with distilled water, representing $106,424,955,1698$, and $2654 \mu \mathrm{g} \mathrm{mL} \mathrm{m}^{-1}$ of $\mathrm{Au}$ and $98,392,883,1569$, and $2452 \mu \mathrm{g} \mathrm{mL}^{-1}$ of Ag.

Microbiological evaluation was performed using a modified agar dilution method. Briefly, Muller-Hinton agar was hydrated (77\%), sterilized, and mixed with $1 \mathrm{~mL}$ of nanoparticle solution. The final volume was completed to $20 \mathrm{~mL}$ with sterilized medium. The modified agar was slowly mixed, poured into petri dishes for gelation, and posteriorly incubated $24 \mathrm{~h}$ for microbiological control. Final concentrations for modified Agar-NP media were 5, 20, 46, 81, 126, and $182 \mu \mathrm{g} \mathrm{mL}^{-1}$ of Au and 5, 19, 42, 75, 117, and $168 \mu \mathrm{g} \mathrm{mL}^{-1}$ for Ag.

To determine the effect of the UBI peptide, different concentrations, ranging from $20 \mu \mathrm{M}\left(0.33 \mu \mathrm{g} \mathrm{mL}^{-1}\right)$ to $0.06 \mu \mathrm{M}$ $\left(0.001 \mu \mathrm{g} \mathrm{mL}^{-1}\right)$, were evaluated. Each experiment was carried out in triplicate.

Inoculation was conducted in accordance with the CLSI M07-A9 method [30], using a suspension equivalent to a 0.5 McFarland standard of $E$. coli and $P$. aeruginosa (1 to $2 \times$ $10^{8}$ colony-forming units; $\left.\mathrm{CFU}\right)$. Appropriate dilutions were made from $10^{-1}$ to $10^{-6}$. Inoculation was performed with $2 \mu \mathrm{L}$ of the $10^{-1}$ dilution. Five inoculums were placed in the previously prepared agar to obtain approximately $10^{4} \mathrm{CFU}$ per spot. Aliquots of $10^{-6}$ were cultured in nanoparticle-free agar as a growth control. Inoculated plates were inverted and incubated at $35 \pm 2^{\circ} \mathrm{C}$ for $16-20$ hours as an end point. Growth of colonies was posteriorly evaluated.

2.7. Statistical Evaluation. Results were expressed as mean \pm standard deviation (SD). Statistical significance was verified through Student's $t$-test, considering a significance of $p<$ 0.05 , unless otherwise indicated.
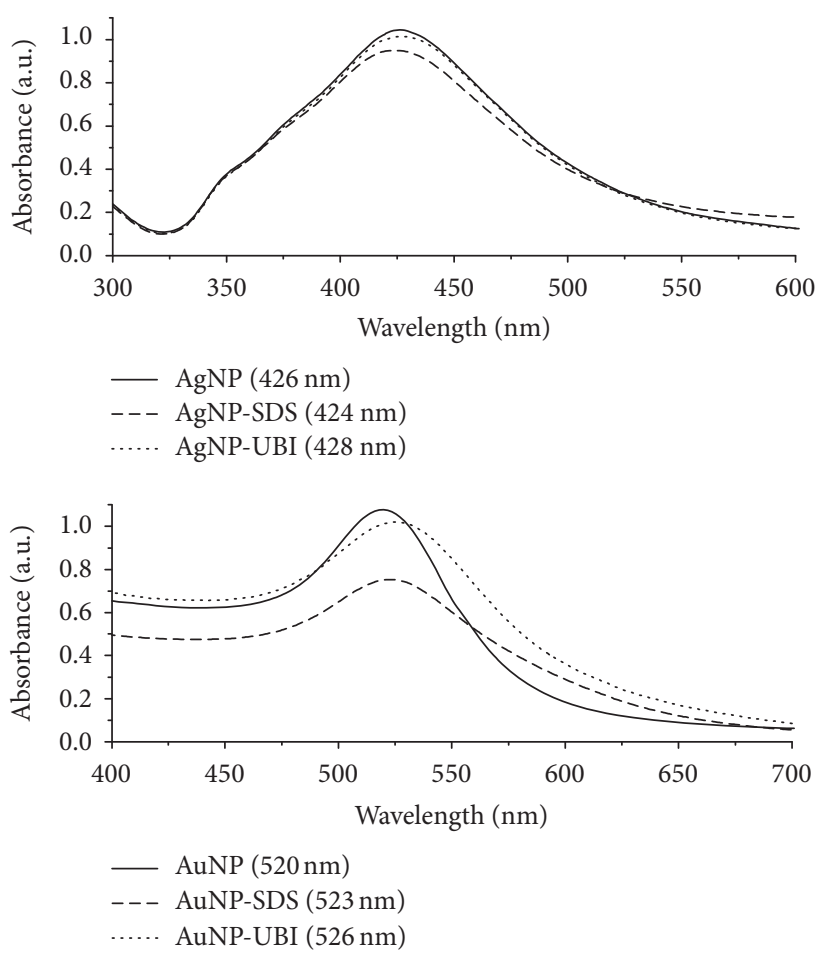

FIGURE 1: UV-Vis spectra of silver and gold nanoparticles stabilized with SDS and functionalized with the UBI peptide.

\section{Results and Discussion}

\subsection{Chemical Characterization}

3.1.1. UV-Vis Spectroscopy. The citrate-stabilized AuNP and AgNP spectra showed a surface plasmon resonance band at $520 \mathrm{~nm}$ and $426 \mathrm{~nm}$ (Figure 1), respectively. It is wellknown that size, shape, and chemical environment modify the dielectric constant at the nanoparticle surface [31]. A redshift was observed in the functionalized systems of AuNPSDS ( $3 \mathrm{~nm})$, AuNP-UBI $(6 \mathrm{~nm})$, and AuNP ( $4 \mathrm{~nm}$ ), which is associated with an increase in the local refractive index at the nanoparticle surface [32]. A blue-shift was observed for AgNP-SDS ( $2 \mathrm{~nm}$ ), which could be related to stabilization by the coating surfactant, promoting the dispersion of small aggregates.

The stability of functionalized NPs in water was monitored by means of an SPR band for 6 months. There were not significant modifications in intensity and width of the SPR band.

3.1.2. Particle Size and Zeta Potential. TEM images of AgNP, AgNP-UBI, AuNP, and AuNP-UBI showed monodispersed solutions. Additionally, an increase in the volume mean diameter was observed as an effect of peptide conjugation. The interaction of stabilizer/peptide and peptide conjugation was observed as a low electronic density around the gold nanoparticle cores (Figure 2(b)).

The mean hydrodynamic diameters, determined by DLS, showed no significant changes in stabilized SDSnanoparticles. Molero et al. determined that SDS-micelle 


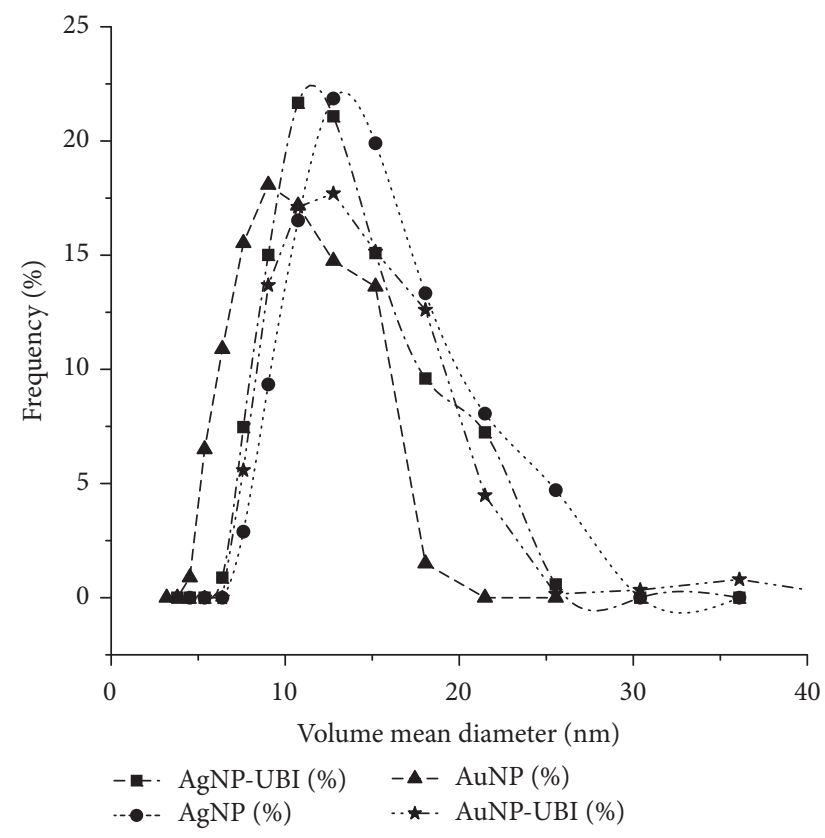

(a)

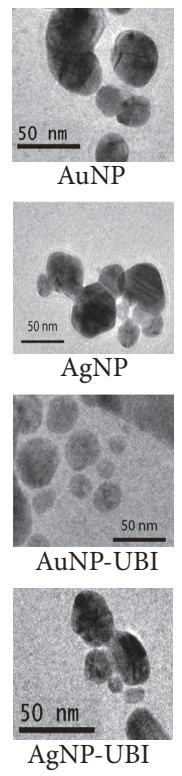

(b)

FIGURE 2: Particle size analysis determined by DLS (a) and TEM (b).

formation at concentrations below $8 \mathrm{mM}$ has no significant increase on micellar diameter [33]. Measured diameters were $12.3 \pm 3.9 \mathrm{~nm}$ and $14.4 \pm 4.3 \mathrm{~nm}$ for AgNP and AgNPUBI and $14.5 \pm 5.7$ and $16.5 \pm 6.2 \mathrm{~nm}$ for AuNP and AuNP-UBI, respectively (Figure 2(a)). Nanoparticles did not show a significant change in dispersity; the slight increase in diameters was attributed to adsorbed peptide and its significant contribution to molecular weight. The $Z$-potential of AgNP and AuNP was $96.5 \mathrm{mV}$ and $63.0 \mathrm{mV}$, respectively, and $113.9 \mathrm{mV}$ and $82 \mathrm{mV}$ for the AgNP-UBI and AuNPUBI, correspondingly, indicating that the peptide interaction conferred a high colloidal stability to the nanosystems.

3.1.3. Infrared Spectroscopy. The main vibrational frequencies of the primary amine of Lys $\left(3281 \mathrm{~cm}^{-1}\right)$ and the amide I (at $1619 \mathrm{~cm}^{-1}, \mathrm{C}=\mathrm{O}$ stretch) of the secondary amide observed in the UBI spectrum (Figure 3(a)) were no longer seen as defined bands in the AuNP-UBI and AgNP-UBI spectra (Figures 3(b) and 3(c)). Instead, broad bands centered at $3294 \mathrm{~cm}^{-1}$ (Figure 3(b)) and $3257 \mathrm{~cm}^{-1}$ (Figure 3(c)) corresponding to the secondary amide and bands at $1719 \mathrm{~cm}^{-1}$, $1589 \mathrm{~cm}^{-1}$ (Figure 3(b)), $1656 \mathrm{~cm}^{-1}$, and $1573 \mathrm{~cm}^{-1}$ (Figure $3(\mathrm{c})$ ), related to primary amide I or II, are observed (in the solid state, amides I and II may overlap). The interaction of the $\mathrm{NH}_{2}$-lysine with the NP surface is also revealed in the $\mathrm{CH}_{2}-\mathrm{NH}_{2}$ band position, which changed from $1179 \mathrm{~cm}^{-1}$ $\left(\mathrm{CH}_{2} / \mathrm{NH}_{2}\right.$ twisting vibration) to $1394 \mathrm{~cm}^{-1}$ (Figure 3(b)) or $1389 \mathrm{~cm}^{-1}$ (Figure $\left.3(\mathrm{c})\right)\left(\mathrm{CH}_{2}\right.$ wagging vibration) as a result of a significant change of symmetry in the peptide due to the NP-Lys-UBI interaction. This supports the argument that the main bond in NP-UBI is through the amine NP- $\mathrm{NH}_{2}$-LysUBI (Figure 3).
The AgNPs spectra are characterized by weak and broad band centred at $3369 \mathrm{~cm}^{-1}$ from $(\mathrm{COO}-\mathrm{H})_{\text {st }}$ vibrations, a broad and intense band from $(\mathrm{C}-\mathrm{H})_{\delta}$ vibrational modes from citrate skeletal are localized at $1390 \mathrm{~cm}^{-1}$, and additional vibrational modes $\left(832-1100 \mathrm{~cm}^{-1}\right)$ from citrate are observed. AuNP shows strong bands between $3000-2700 \mathrm{~cm}^{-1}$ assigned to $\left(>\mathrm{C}-\mathrm{H}_{2}\right)_{\text {st sy }}, v_{\text {as }}\left(>\mathrm{C}-\mathrm{H}_{2}\right)_{\text {st as }}$ vibrational modes and $1118-1258 \mathrm{~cm}^{-1}$ assigned to (COO-) $)_{\text {st sy }}$. In both cases, predominant vibrational modes correspond to functional groups of the citrate employed as a reducer agent and stabilizer (see Supplemental Material Figure 1 in Supplementary Material available online at https://doi.org/10.1155/2017/5831959). Characteristic spectra of dodecyl sulphate were obtained. SDSstabilized NPs spectra were characterized by strong, multiple, and well defined bands attributed principally to $\left(-\mathrm{CH}_{3}\right)_{\delta \text { as }}$ between 1470 and $1430 \mathrm{~cm}^{-1},(\mathrm{~S}=\mathrm{O})_{\text {st as }}$ at $1225-980 \mathrm{~cm}^{-1}$, $(\mathrm{S}=\mathrm{O})_{\text {st sy }}$ at $1200-1000 \mathrm{~cm}^{-1},(\mathrm{C}-\mathrm{O})_{\text {st }}$ at $1200-1080 \mathrm{~cm}^{-1}$, $(\mathrm{S}-\mathrm{O})_{\mathrm{st}}$ at $870-690 \mathrm{~cm}^{-1}$, and $\left(\mathrm{C}-\mathrm{H}_{2}\right)_{\mathrm{g}}$ between 770 and $720 \mathrm{~cm}^{-1}$ (see Supplemental Material Figure 2). The spectra of UBI show a broad band between 3100 and 3500, corresponding to $(\mathrm{N}-\mathrm{H})_{\mathrm{st}}, \mathrm{H}$-bonded $(\mathrm{O}-\mathrm{H})_{\mathrm{st}}$, and $(\mathrm{N}-\mathrm{H})_{\mathrm{st}}$ free vibrational modes. Strong bands corresponding to amide I $(\mathrm{C}=\mathrm{O})_{\text {st }}$ and amide II $(\mathrm{N}-\mathrm{C}=\mathrm{O})_{\text {st sy }}$ can be observed between $1655-1630 \mathrm{~cm}^{-1}$ and $1560-1510 \mathrm{~cm}^{-1}$, respectively (Figure 3(a)). Peptide-functionalized silver and gold NPs (Figures 3(b) and 3(c)) show vibrational modes associated with UBI. Vibrational modes of $(\mathrm{C}-\mathrm{H})_{\mathrm{st}}$ near $2925 \mathrm{~cm}^{-1}$ and $\left(-\mathrm{CH}_{2}-\mathrm{O}-\right)$ st, between 2880 and $2830 \mathrm{~cm}^{-1}$, are attributable to the hydrocarbon chain and ester bond from the SDS employed as a stabilizing agent. 


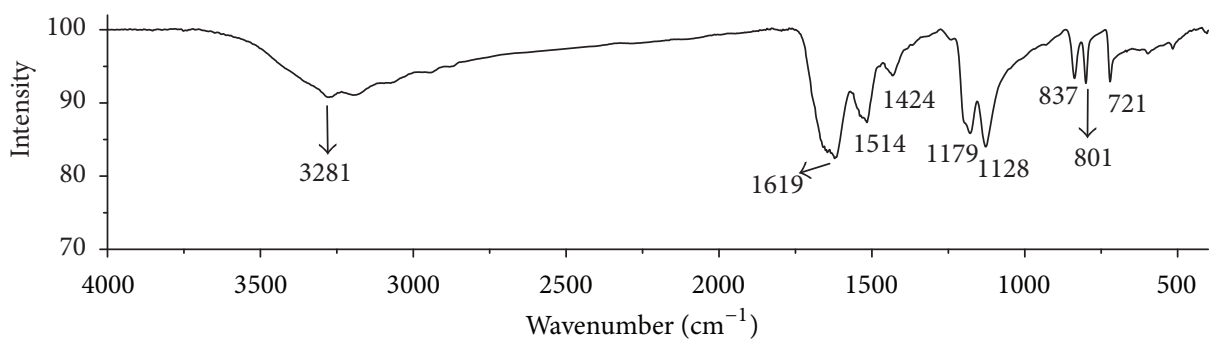

(a)

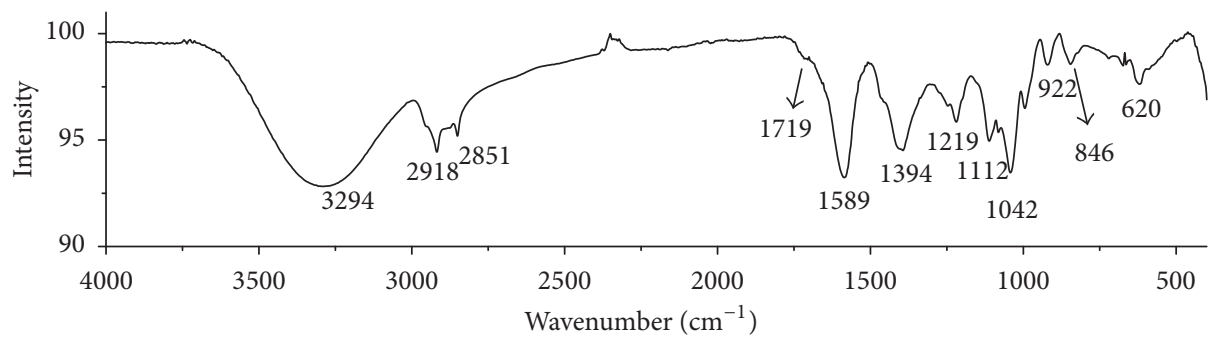

- AgNP-UBI (29-41)

(b)

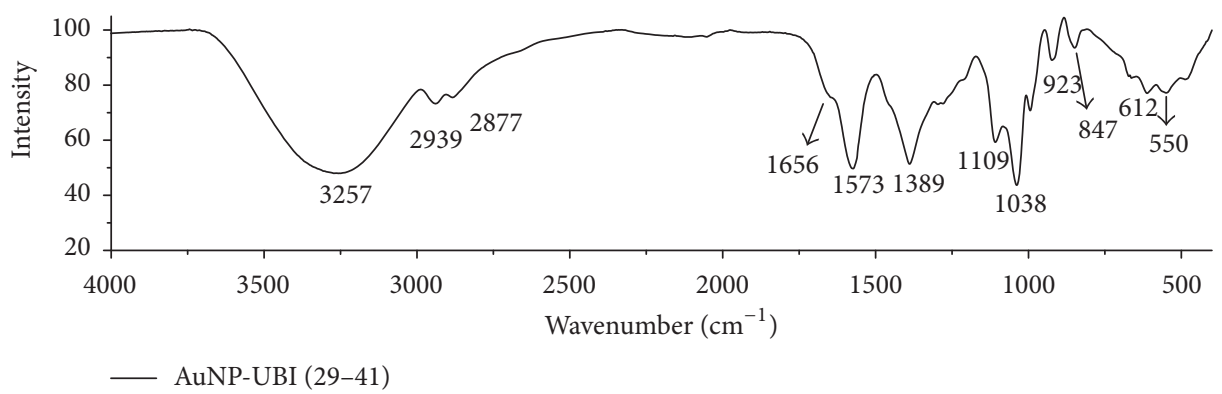

(c)

FIGURE 3: IR-FT spectra of (a) UBI peptide and functionalized nanoparticles, (b) AgNP-UBI, and (c) AuNP-UBI.

3.1.4. Raman Spectroscopy. Significant spectral differences were observed in functionalized silver and gold NPs with respect to citrate-stabilized suspensions. Absence of Raman signalling was observed for AuNP-citrate and AgNP-citrate (Figures 4(a) and 4(c)), whereas peptide-functionalized NPs (Figures $4(\mathrm{~b})$ and $4(\mathrm{~d})$ ) showed broad bands in the region of 1800 to $800 \mathrm{~cm}^{-1}$. In both systems, significant bands attributable to amide $\mathrm{I}(\mathrm{C}=\mathrm{O})_{\mathrm{st}}$, amide II $(\mathrm{N}-\mathrm{H})_{\mathrm{st}}$, and amide III $(\mathrm{C}-\mathrm{N})_{\text {st }}$ were observed near 1600,1550 , and $1231 \mathrm{~cm}^{-1}$, respectively. Additionally, bands with a significant contribution in intensity were observed at 1574 and $1542 \mathrm{~cm}^{-1}$, which could be attributable to $\left(\mathrm{C}-\mathrm{N}_{3}\right)_{\text {st }}$ from guanidine groups of arginine, present in high concentration in the peptide. Skeletal chains of aliphatic $\left(-\mathrm{CH}_{2}-\right)$ and methylene groups $\left(-\mathrm{CH}_{3}\right)$ could contribute to frequencies near 1410 and $1422 \mathrm{~cm}^{-1}$. Additional vibrational bands of Tyr could be assigned at 685 and $820 \mathrm{~cm}^{-1}$. The latter is caused by characteristic Fermi resonance between the in-plane breathing mode of the phenol ring and an overtone of the out-of-plane deformation mode. FT-IR and Raman spectroscopy were used to confirm the surface modification of silver or gold nanoparticles with the UBI peptide.
The vibrational modes from functionalized nanoparticles are hardly sensitive to conformational changes and electrostatic interactions; shifts in vibrational modes from the amide II region are correlated with the increase of strength of van der Waal interactions with NP surfaces. The C-H stretching band appears as superimposed bands under the prominent $\mathrm{O}-\mathrm{H}$ stretching in functionalized nanoparticles, with respect to SDS or citrate-stabilized nanoparticles. This gives good evidence that the molecules increase their intermolecular hydrogen bonds and suggests that electrostatic interactions play a determinant role in peptides bound to NP surfaces.

TEM and spectroscopy techniques demonstrated that AgNPs and AuNPs were functionalized with the UBI peptide. The IR spectrum of nanoparticles showed vibrational modes from citrate, SDS, or peptides adsorbed onto the nanoparticle surface.

3.1.5. XP Spectroscopy. The AuNP spectrum (Figure 5(a)) showed two main peaks corresponding to the binding energies (BE, eV) of electrons in Au 4 f orbitals at $87.2 \mathrm{eV}\left(\mathrm{Au} 4 \mathrm{f}_{5 / 2}\right)$ and $83.3 \mathrm{eV}\left(\mathrm{Au} 4 \mathrm{f}_{7 / 2}\right)$ and the deconvoluted spectrum for $\mathrm{Au} 4 \mathrm{f}_{7 / 2}$ showed peaks at 83.9 and $83.2 \mathrm{eV}$, the first probably 


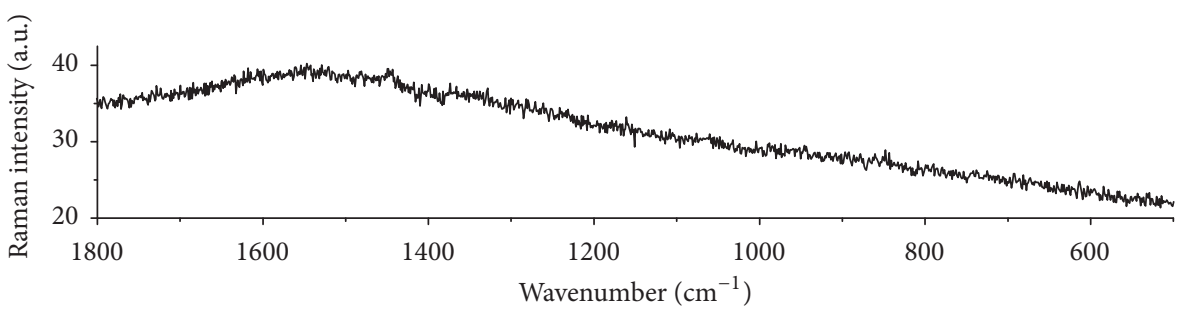

- AgNP-Cit

(a)

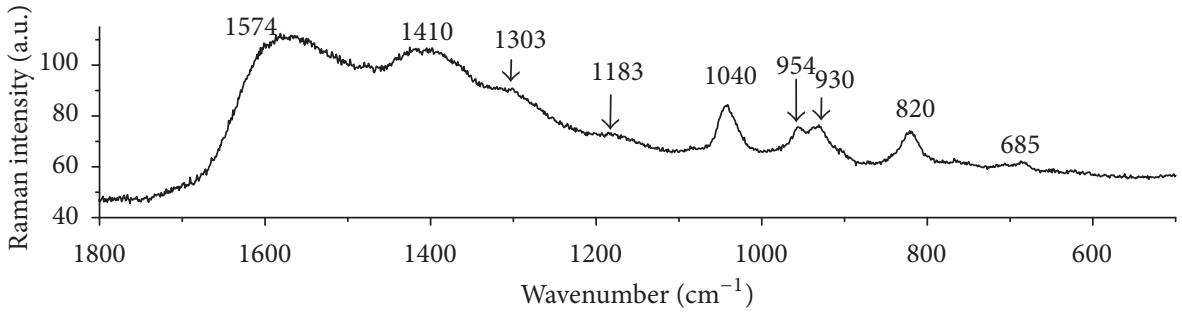

- AgNP-UBI (29-41)

(b)

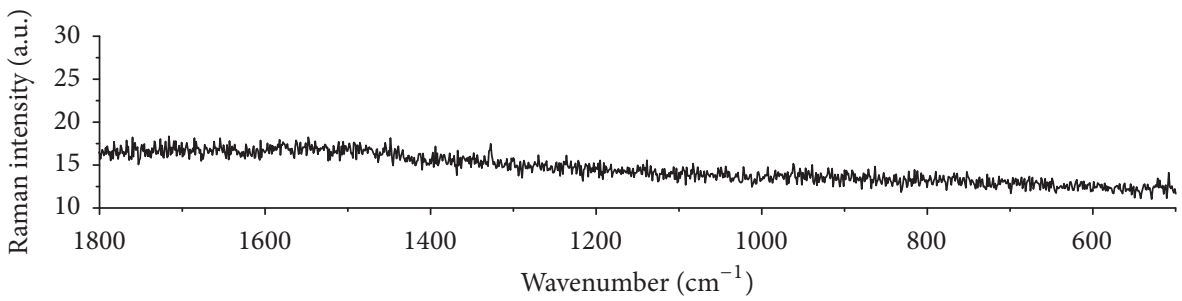

- AuNP-Cit

(c)

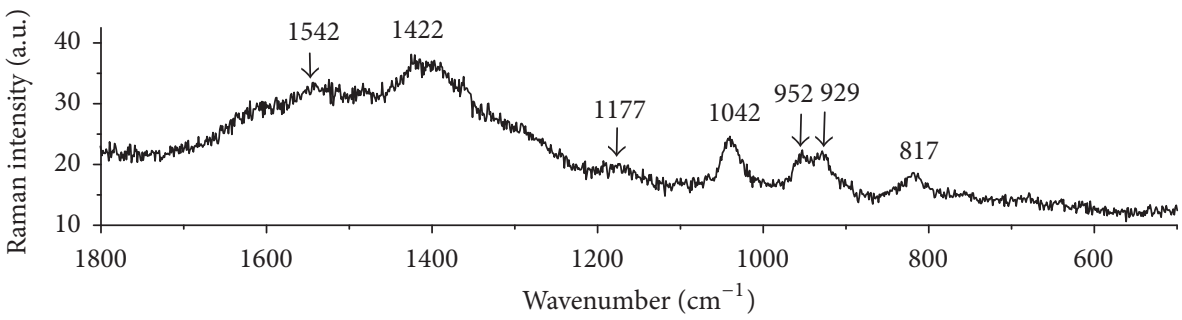

AuNP-UBI (29-41)

(d)

Figure 4: Raman spectra for (a) AgNP-citrate, (b) AgNP-UBI, (c) AuNP-citrate, and (d) AuNP-UBI.

due to weak bond with oxygen by electrostatic forces to metallic gold core and phosphate groups of surfactant. For Ag spectrum (Figure 5(b)) $3 \mathrm{~d}_{3 / 2-5 / 2}$ core level binding energies appear at 374.1 and $368.1 \mathrm{eV}$, respectively, in good agreement with bulk silver metallic values, corresponding to the presence of fcc metallic silver structures found in nanoparticles. Deconvoluted $\mathrm{Ag} 3 \mathrm{~d}_{5 / 2}$ spectra can be fitted in terms of two different chemically species with binding energies at 368.5 and $367.8 \mathrm{eV}$, assigned to metallic silver $(\mathrm{Ag} 0)$ and silver ions in $\mathrm{Ag}_{2} \mathrm{O}(\mathrm{Ag}+)$, respectively, in agreement with previous reports $[34,35]$.

3.2. Microbiological Assay. Table 1 shows the minimum NP concentrations required to inhibit growth of $E$. coli and $P$. aeruginosa. A statistically significant difference was observed between noncapped gold and silver nanoparticles, whereas AuNP and gold-functionalized nanoparticles seem to need high NP concentration to produce a significant deleterious effect on microbial growth. AgNPs showed an important effect over both evaluated microorganisms. Significant activity was observed with functionalized NPs when compared with citrate or SDS-stabilized NPs. The free peptide did not show any inhibitory effect at the evaluated concentrations.

The mechanism of nanoparticle interaction with ionic surfactants has not been completely elucidated yet. However, [36] suggests a possible mechanism of SDS distribution on the NP surface, in which the hydrophilic groups of the surfactant molecules are adsorbed onto the nanoparticle surface and the 


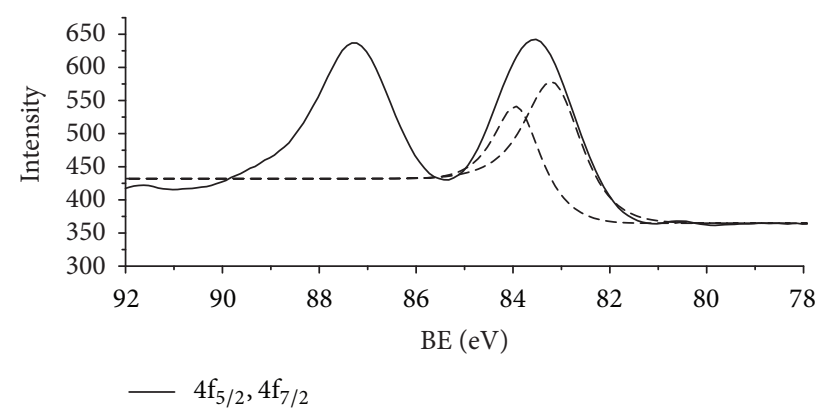

(a) AuNP-UBI

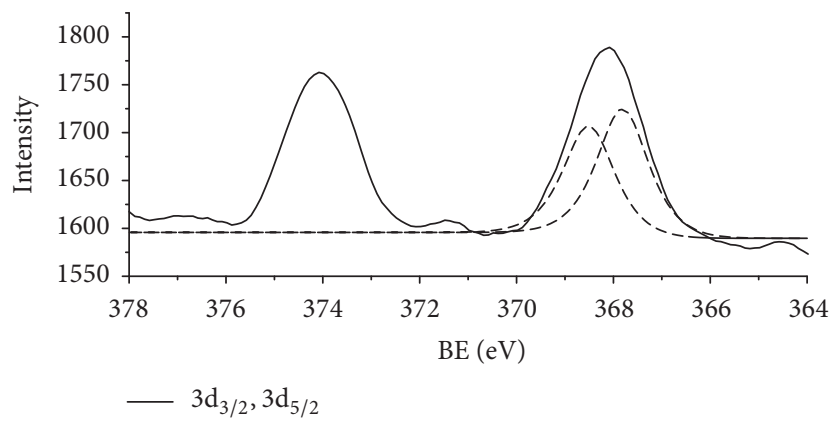

(b) AgNP-UBI

Figure 5: XPS spectra for (a) AuNP-UBI and (b) AgNP-UBI.

hydrophobic tails are directed outward to form the first layer. Consequently, a counter-layer is oriented the opposite way, resulting in interpenetration of the surfactant hydrophobic tails between the two layers with hydrophilic groups headed outward [13]. The addition of cationic surfactant is justified by at least two reasons. The first is an increase of colloidal stability of zero valent nanoparticles, enhanced by steric repulsion from adsorbed surfactants and the balance in electrostatic forces, following a possible mechanism in which surfactant molecules form a compact micellar layer with hydrophilic groups oriented to the nanoparticle surface. The second justification is related to the increase of peptide interaction with the nanoparticle surface through the use of the surfactant bilayer's capability to adsorb and stabilize the peptide by electrostatic interactions between anionic, cationic, and nonpolar domains of the peptide. Additionally, it has been reported that ionic surfactants are adsorbed in a less-compact mode at the nanoparticle surface compared to nonionic surfactants [37]. Established mechanisms have demonstrated that silver nanoparticles have a higher antimicrobial activity compared to free silver ions. Additionally, the $\mathrm{Ag}^{+}$ions delivered by nanoparticles located within the cell increase the antibacterial activity.

Reported bactericidal effects from gold NPs are still controversial. A great variability in MIC exists, attributable mainly to microorganism type, specific conditions of particular procedures, as well as diffusion mechanisms in growth media, support materials (applicable in disc procedures), biofilm formation, and so forth. It is important to note the differences in analytical procedures for microbiological evaluation; in most cases, analysis was carried out by disk
TABLE 1: Minimum concentrations needed to inhibit the growth of bacterial cells.

\begin{tabular}{lcc}
\hline & \multicolumn{2}{c}{ MIC $\left.(\mu \mathrm{g} \mathrm{mL})^{-1}\right)^{*}$} \\
\hline AuNP & $>182$ & P. aeruginosa \\
AuNP-SDS & $>182$ & $>182$ \\
AuNP-UBI & $>182$ & $>182$ \\
AgNP & $130.6 \pm 0.5$ & $>182$ \\
AgNP-SDS & $114.7 \pm 1.7$ & $>168$ \\
AgNP-UBI & $89.3 \pm 1.9$ & $150 \pm 10$ \\
${ }^{*}$ MIC expressed in gold, silver, or peptide concentration required to inhibit \\
bacterial growth.
\end{tabular}

diffusion assay on Müller-Hinton agar plates. However, in our experience, there are significant disadvantages in such procedure. We have observed that the interaction of nanoparticles with adsorbent materials does not demonstrate the same behaviour as with the desorption process. Interaction with fibres could modify nanoparticle nature observed by significant alteration in nanoparticle-support colour. In this sense, it is difficult to establish a relationship between previous reports based on exposure concentrations.

The NP microbicidal effect has been associated with bacteria class. In E. coli, complete growth was impeded with AgNP concentrations above $75 \mu \mathrm{g} \mathrm{mL}^{-1}$. However, evidence demonstrates that the shape of AgNPs determines their deleterious effects. The most effective antibacterial activity has been observed with triangular nanoparticles [38, 39]. In this research, synthetized silver nanoparticles showed a variable distribution in nanoparticle shape, with a predominant spheroidal form. These and other factors associated with the particular development of the methodology could be responsible for the increase of the MIC in noncapped AgNPs. For example, Rai et al. reported a weak bactericidal activity ( $<10 \%$ of inhibition) on $S$. aureus exposed for $6 \mathrm{~h}$ to $500 \mu \mathrm{g} \mathrm{mL}^{-1}$ of AgNPs of 23- to $52 \mathrm{~nm}$ diameter [18]. The absence of inhibition was most likely attributable to the presence of a peptidoglycan layer on the cell walls of $S$. aureus, which does not allow for the penetration of AgNPs. Umamaheswari et al. reported $\mathrm{MCI}_{80}$ on E. coli, S. typhi, $P$. aeruginosa, and $K$. pneumoniae, which ranged from 20 to $40 \mu \mathrm{g} \mathrm{mL}^{-1}$ with a damage mechanism mediated by ROS and loss of membrane integrity [40].

The diversity in results showed that microbicidal effects are limited to certain types of microorganisms and the interaction with the cellular microenvironment, such as cell wall, glycocalyx, slime layer, or biofilm formation, since differences in peptidoglycan composition, variations in the peptide stem, and particular cross-linking determine nanoparticle diffusion. Additionally, certain variations were observed between members of the same species and the species themselves, depending on growth conditions such as growth phase, media composition, and presence of antibiotics [41].

In one particular case, a concentration of $182 \mu \mathrm{g} \mathrm{m}^{-1}$ of gold nanoparticles was insufficient to produce cellular damage in Gram-negative microorganisms (Figure 6(a)), 

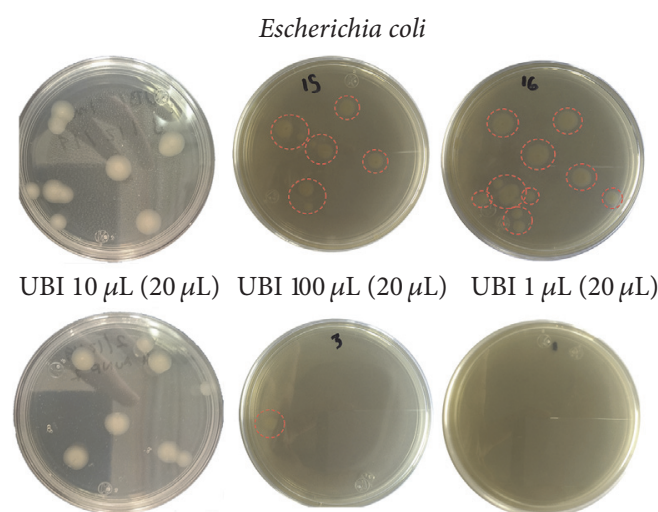

AuNP $(182 \mu \mathrm{g} / \mathrm{mL}) \operatorname{AgNP}(116 \mu \mathrm{g} / \mathrm{mL}) \operatorname{AgNP}(168 \mu \mathrm{g} / \mathrm{mL})$

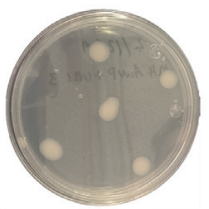

AuNP-UBI

$(182 \mu \mathrm{g} / \mathrm{mL})$

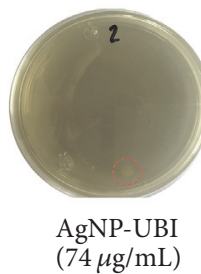

(a)

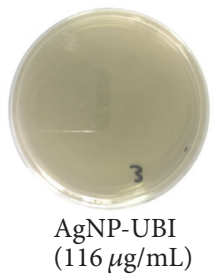

$(116 \mu \mathrm{g} / \mathrm{mL})$
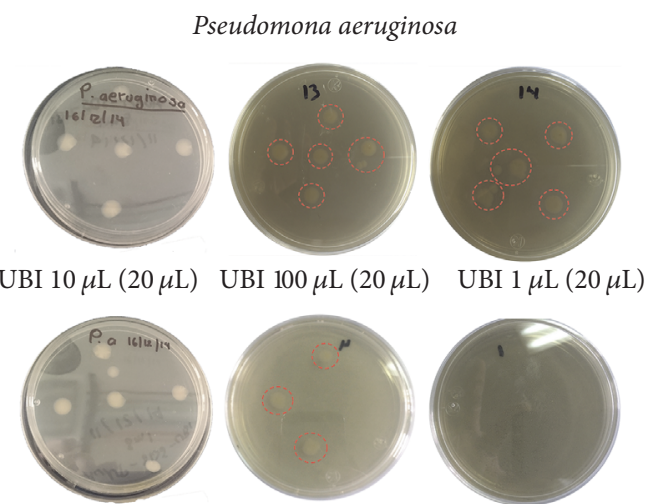

$\operatorname{AuNP}(182 \mu \mathrm{g} / \mathrm{mL}) \operatorname{AgNP}(116 \mu \mathrm{g} / \mathrm{mL}) \operatorname{AgNP}(168 \mu \mathrm{g} / \mathrm{mL})$

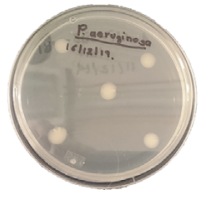

AgNP-UBI

$(>182 \mu \mathrm{g} / \mathrm{mL})$
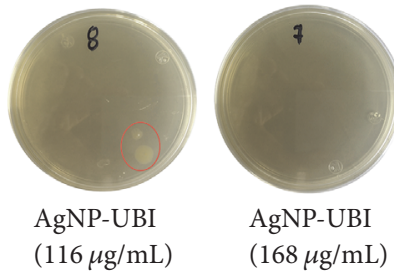

(b)

FIGURE 6: Effect on bacterial growth of Escherichia coli and Pseudomonas aeruginosa exposed to UBI peptide, silver and gold nanoparticles, and conjugate AuNP-UBI or AgNP-UBI.

but a significant increase in inhibition was observed with silver nanoparticles. Specifically, a decrease of $31.6 \%$ for E. coli and $38 \%$ for $P$. aeruginosa was observed when the peptide was conjugated to silver (Figure 6(b)). We propose that the enhanced mechanisms of the antimicrobial agent could be attributable to at least two effects. The first is the local concentration increase of peptide surrounding the nanoparticle and the intrinsic effect of the nanoparticle, including the release of silver ions from the nanoparticle core. As with silver nanoparticles, the gold cores increase the local concentration of peptide. However, the damage mechanisms differ significantly with respect to AgNP. The nature of the damage produced by silver nanoparticles has been widely studied, even though the specific mechanisms have not yet been elucidated.

We demonstrated that the antimicrobial activity produced by silver nanoparticles was modified when antimicrobial peptides were bound to the nanoparticle surface. The effect was determined using two microorganisms representative of the Gram-negative group, E. coli and P. aeruginosa. However, in order to prove their therapeutic potential, the AgNP-UBI conjugate needs to be tested on in vivo models. Silver nanoparticles conjugated to antimicrobial peptides increase the antibacterial activity against Gram-negative bacteria providing a promising alternative therapy for topical infections.

\section{Conclusions}

Currently, an intense investigation in nanotechnology and its applications in infectious or contagious diseases has led to the development of antimicrobial formulations from nanoparticles that act as an effective bactericidal agent. In this study, it was demonstrated that an increase in the antibacterial activity against Gram-negative bacteria appears when silver nanoparticles are capped with the UBI antimicrobial peptide, probably due to the multimeric or polyvalent arrangement of ligands distributed on the nanoparticle surface. Additional studies are required to understand the structure of multivalent nanoparticles and stabilization mechanisms not yet elucidated.

\section{Conflicts of Interest}

The authors declare that they have no conflicts of interest.

\section{Acknowledgments}

This work was supported by the PROMEP-CA-68 (2013) project and The International Atomic Energy Agency (Contract no. 18358). The authors are gratefully acknowledged for skillful analytical and instrumental assistance to "Laboratorio Nacional de Investigación y Desarrollo de Radiofármacos, CONACyT.”

\section{References}

[1] S. Bardhan, K. Kundu, S. Das, M. Poddar, S. K. Saha, and B. K. Paul, "Formation, thermodynamic properties, microstructures and antimicrobial activity of mixed cationic/non-ionic surfactant microemulsions with isopropyl myristate as oil," Journal of Colloid and Interface Science, vol. 430, pp. 129-139, 2014. 
[2] D. M. Smith, J. K. Simon, and J. R. Baker, "Applications of nanotechnology for immunology," Nature Reviews Immunology, vol. 13, no. 8, pp. 592-605, 2013.

[3] L. Zhao, A. Seth, N. Wibowo et al., "Nanoparticle vaccines," Vaccine, vol. 32, no. 3, pp. 327-337, 2014.

[4] L. Azhar Shekoufeh B and F. Lotfipour, "Magnetic nanoparticles for antimicrobial drug delivery," Pharmazie, vol. 67, no. 10, pp. 817-821, 2012.

[5] L. Rizzello and P. P. Pompa, "Nanosilver-based antibacterial drugs and devices: mechanisms, methodological drawbacks, and guidelines," Chemical Society Reviews, vol. 43, no. 5, pp. 1501-1518, 2014.

[6] L.-E. Shi, Z.-H. Li, W. Zheng, Y.-F. Zhao, Y.-F. Jin, and Z.-X. Tang, "Synthesis, antibacterial activity, antibacterial mechanism and food applications of $\mathrm{ZnO}$ nanoparticles: a review," Food Additives and Contaminants Part A: Chemistry, Analysis, Control, Exposure and Risk Assessment, vol. 31, no. 2, pp. 173-186, 2014.

[7] M. Kaur, T. Garg, G. Rath, and A. K. Goyal, "Current nanotechnological strategies for effective delivery of bioactive drug molecules in the treatment of tuberculosis," Critical Reviews in Therapeutic Drug Carrier Systems, vol. 31, no. 1, pp. 49-88, 2014.

[8] Q. H. Tran, V. Q. Nguyen, and A. Le, "Silver nanoparticles: synthesis, properties, toxicology, applications and perspectives," Advances in Natural Sciences: Nanoscience and Nanotechnology, vol. 4, no. 3, article 20, 2013.

[9] H. J. Lee, S. G. Lee, E. J. Oh et al., "Antimicrobial polyethyleneimine-silver nanoparticles in a stable colloidal dispersion," Colloids and Surfaces B: Biointerfaces, vol. 88, no. 1, pp. 505-511, 2011.

[10] P. Li, J. Li, C. Wu, Q. Wu, and J. Li, "Synergistic antibacterial effects of $\beta$-lactam antibiotic combined with silver nanoparticles," Nanotechnology, vol. 16, no. 9, pp. 1912-1917, 2005.

[11] C. G. Kumar, S. K. Mamidyala, M. N. Reddy, and B. V. S. Reddy, "Silver glyconanoparticles functionalized with sugars of sweet sorghum syrup as an antimicrobial agent," Process Biochemistry, vol. 47, no. 10, pp. 1488-1495, 2012.

[12] L. Liu, J. Yang, J. Xie et al., “The potent antimicrobial properties of cell penetrating peptide-conjugated silver nanoparticles with excellent selectivity for Gram-positive bacteria over erythrocytes," Nanoscale, vol. 5, no. 9, pp. 3834-3840, 2013.

[13] L. Kvítek, A. Panáček, J. Soukupová et al., "Effect of surfactants and polymers on stability and antibacterial activity of silver nanoparticles (NPs)," Journal of Physical Chemistry C, vol. 112, no. 15, pp. 5825-5834, 2008.

[14] Y. Zhou, Y. Kong, S. Kundu, J. D. Cirillo, and H. Liang, "Antibacterial activities of gold and silver nanoparticles against Escherichia coli and bacillus Calmette-Guérin," Journal of Nanobiotechnology, vol. 10, article 19, 2012.

[15] M. Demurtas and C. C. Perry, "Facile one-pot synthesis of amoxicillin-coated gold nanoparticles and their antimicrobial activity," Gold Bulletin, vol. 47, no. 1-2, pp. 103-107, 2014.

[16] H. Gu, P. L. Ho, E. Tong, L. Wang, and B. Xu, "Presenting vancomycin on nanoparticles to enhance antimicrobial activities," Nano Letters, vol. 3, no. 9, pp. 1261-1263, 2003.

[17] B. Saha, J. Bhattacharya, A. Mukherjee et al., "In vitro structural and functional evaluation of gold nanoparticles conjugated antibiotics," Nanoscale Research Letters, vol. 2, no. 12, pp. 614622, 2007.
[18] A. Rai, A. Prabhune, and C. C. Perry, "Antibiotic mediated synthesis of gold nanoparticles with potent antimicrobial activity and their application in antimicrobial coatings," Journal of Materials Chemistry, vol. 20, no. 32, pp. 6789-6798, 2010.

[19] A. Nirmala Grace and K. Pandian, "Antibacterial efficacy of aminoglycosidic antibiotics protected gold nanoparticles-a brief study," Colloids and Surfaces A: Physicochemical and Engineering Aspects, vol. 297, no. 1-3, pp. 63-70, 2007.

[20] A. Schmidtchen and M. Malmsten, "Peptide interactions with bacterial lipopolysaccharides," Current Opinion in Colloid and Interface Science, vol. 18, no. 5, pp. 381-392, 2013.

[21] C. A. De Murphy, F. Gemmel, and J. Balter, "Clinical trial of specific imaging of infections," Nuclear Medicine Communications, vol. 31, no. 8, pp. 726-733, 2010.

[22] D. Beiki, G. Yousefi, B. Fallahi et al., "99mtc-Ubiquicidin [29-41], a promising radiopharmaceutical to differentiate orthopedic implant infections from sterile inflammation," Iranian Journal of Pharmaceutical Research, vol. 12, no. 2, pp. 347353, 2013

[23] G. Ferro-Flores, B. E. Ocampo-García, and L. Melendez-Alafort, "Development of specific radiopharmaceuticals for infection imaging by targeting infectious micro-organisms," Current Pharmaceutical Design, vol. 18, no. 8, pp. 1098-1106, 2012.

[24] M. S. Akhtar, M. B. Imran, M. A. Nadeem, and A. Shahid, "Antimicrobial peptides as infection imaging agents: better than radiolabeled antibiotics," International Journal of Peptides, vol. 2012, Article ID 965238, 19 pages, 2012.

[25] S. Saeed, J. Zafar, B. Khan et al., "Utility of ${ }^{99 m}$ Tc-labelled antimicrobial peptide ubiquicidin (29-41) in the diagnosis of diabetic foot infection," European Journal of Nuclear Medicine and Molecular Imaging, vol. 40, no. 5, pp. 737-743, 2013.

[26] J. Kimling, M. Maier, B. Okenve, V. Kotaidis, H. Ballot, and A. Plech, "Turkevich method for gold nanoparticle synthesis revisited," Journal of Physical Chemistry B, vol. 110, no. 32, pp. 15700-15707, 2006.

[27] X. Dong, X. Ji, H. Wu, L. Zhao, J. Li, and W. Yang, "Shape control of silver nanoparticles by stepwise citrate reduction," Journal of Physical Chemistry C, vol. 113, no. 16, pp. 6573-6576, 2009.

[28] L. C. Robles, C. Garcia-Olalla, and A. J. Aller, "Potentiometric titration of gold in ores with potassium iodide," Fresenius' Journal of Analytical Chemistry, vol. 345, no. 6, pp. 441-444, 1993.

[29] G. Xu, X. Qiao, X. Qiu, and J. Chen, "Preparation and characterization of nano-silver loaded montmorillonite with strong antibacterial activity and slow release property," Journal of Materials Science and Technology, vol. 27, no. 8, pp. 685-690, 2011.

[30] CLSI, Methods for Dilution Antimicrobial Susceptibility Tests for Bacteria That Grow Aerobically, Approved Standard M07-A9, Clinical and Laboratory Standards Institute, Wayne, Pa, USA, 8th edition, 2012.

[31] K. L. Kelly, E. Coronado, L. L. Zhao, and G. C. Schatz, “The optical properties of metal nanoparticles: the influence of size, shape, and dielectric environment," Journal of Physical Chemistry B, vol. 107, no. 3, pp. 668-677, 2003.

[32] E. Petryayeva and U. J. Krull, "Localized surface plasmon resonance: nanostructures, bioassays and biosensing-a review," Analytica Chimica Acta, vol. 706, no. 1, pp. 8-24, 2011.

[33] M. Molero, R. Andreu, D. González, J. J. Calvente, and G. LópezPérez, "An isotropic model for micellar systems: application to sodium dodecyl sulfate solutions," Langmuir, vol. 17, no. 2, pp. 314-322, 2001. 
[34] P. Prieto, V. Nistor, K. Nouneh, M. Oyama, M. Abd-Lefdil, and R. Díaz, "XPS study of silver, nickel and bimetallic silver-nickel nanoparticles prepared by seed-mediated growth," Applied Surface Science, vol. 258, no. 22, pp. 8807-8813, 2012.

[35] N. Maiti, S. Thomas, A. Debnath, and S. Kapoor, "Raman and XPS study on the interaction of taurine with silver nanoparticles," RSC Advances, vol. 6, no. 61, pp. 56406-56411, 2016.

[36] Y.-H. Chen and C.-S. Yeh, "Laser ablation method: use of surfactants to form the dispersed Ag nanoparticles," Colloids and Surfaces A: Physicochemical and Engineering Aspects, vol. 197, no. 1-3, pp. 133-139, 2002.

[37] S. K. Meena, S. Celiksoy, P. Schäfer, A. Henkel, C. Sönnichsen, and M. Sulpizi, "The role of halide ions in the anisotropic growth of gold nanoparticles: a microscopic, atomistic perspective," Physical Chemistry Chemical Physics, vol. 18, no. 19, pp. 13246-13254, 2016.

[38] G. Franci, A. Falanga, S. Galdiero et al., "Silver nanoparticles as potential antibacterial agents," Molecules, vol. 20, no. 5, pp. 8856-8874, 2015.

[39] D. Wu, W. Fan, A. Kishen, J. L. Gutmann, and B. Fan, "Evaluation of the antibacterial efficacy of silver nanoparticles against Enterococcus faecalis biofilm," Journal of Endodontics, vol. 40, no. 2, pp. 285-290, 2014.

[40] K. Umamaheswari, R. Baskar, K. Chandru, N. Rajendiran, and S. Chandirasekar, "Antibacterial activity of gold nanoparticles and their toxicity assessment," BMC Infectious Diseases, vol. 14, supplement 3, p. P64, 2014.

[41] J. C. Gumbart, M. Beeby, G. J. Jensen, and B. Roux, "Escherichia coli peptidoglycan structure and mechanics as predicted by atomic-scale simulations," PLoS Computational Biology, vol. 10, no. 2, Article ID e1003475, 2014. 

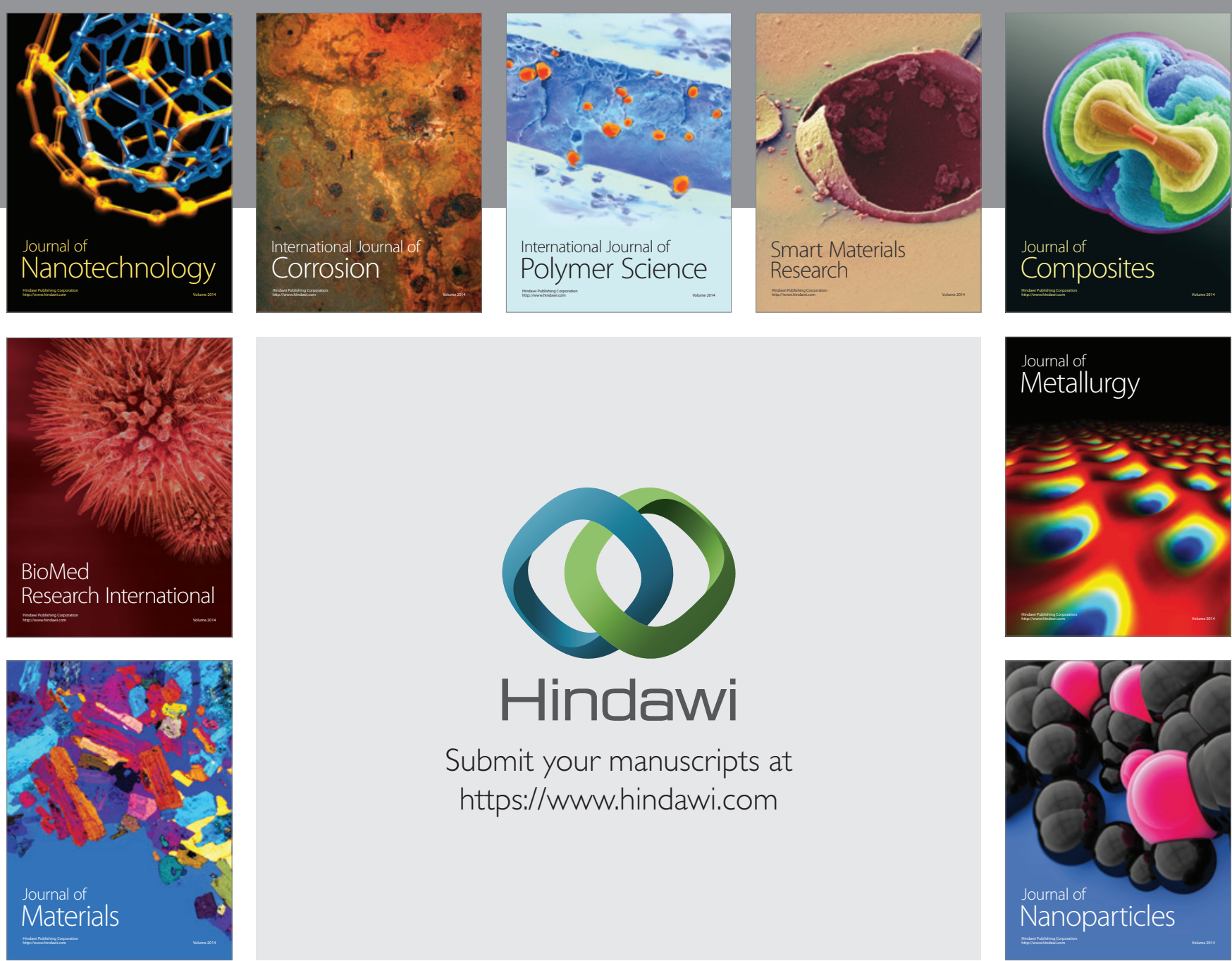

\section{Hindawi}

Submit your manuscripts at

https://www.hindawi.com

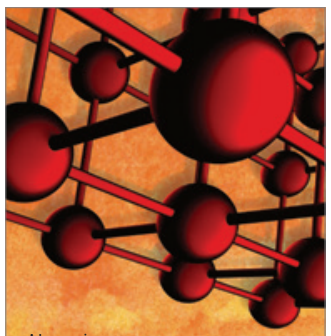

Materials Science and Engineering
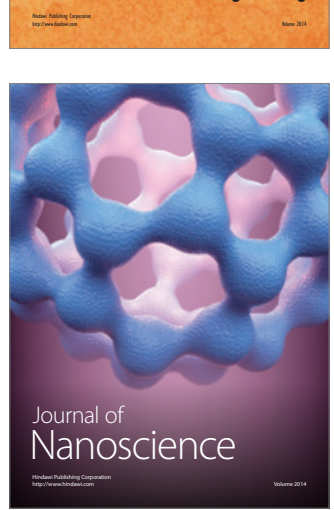
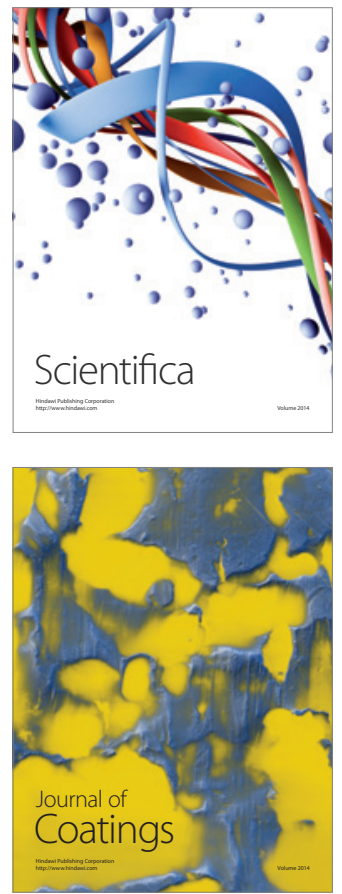
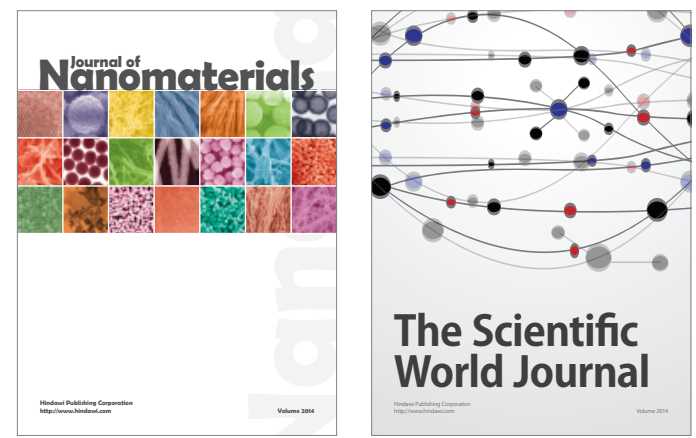

The Scientific World Journal
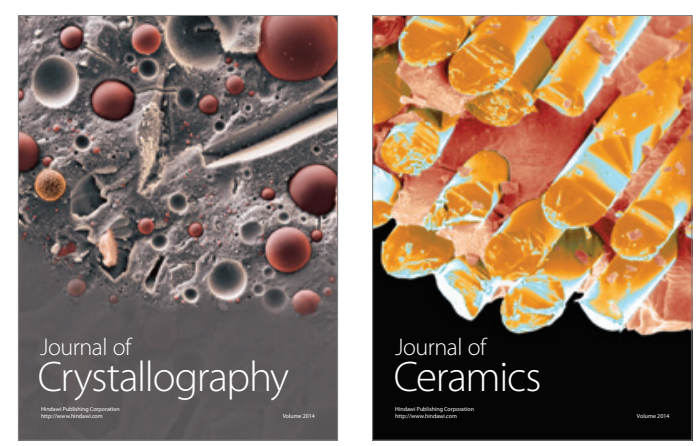
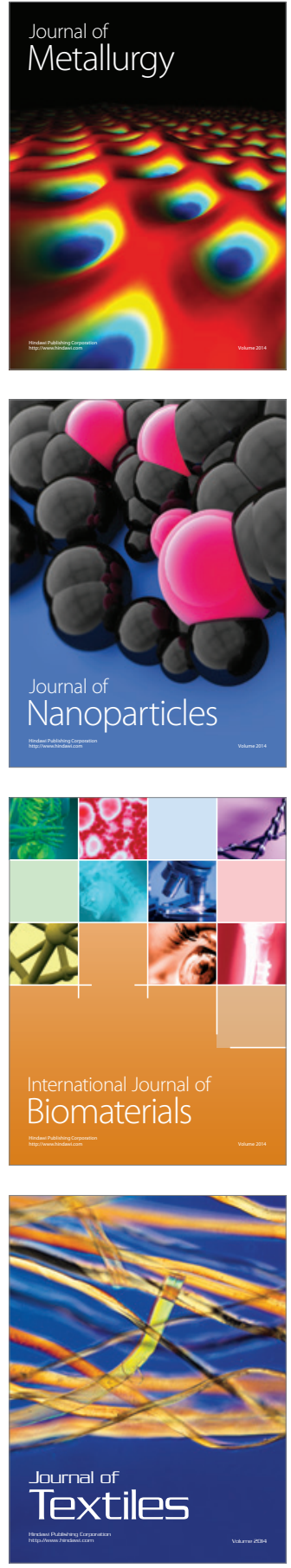